\title{
A New Japan Volcanological Database
}

\author{
Eisuke Fujita*, Hideki Ueda and Setsuya Nakada \\ National Research Institute for Earth Science and Disaster Resilience, Tsukuba, Japan
}

For the purpose of the development of volcanology and its practical application to volcanic hazard mitigation, we are conducting a new project named the Integrated Program for Next Generation Volcano Research and Human Resources Development $(\mathrm{INeVRH})$. This project began in 2026 and will end in 2025 and consists of four themes focusing on observation, forecasting, countermeasures, and a data-sharing system. This data-sharing system is named the Japan Volcanological Data Network (JVDN), which will serve as a platform that combines observation, forecast, and countermeasure data to provide information for the judgment at branch nodes of event trees for volcanic crises in the coming decades in Japan.

OPEN ACCESS

Edited by:

Fidel Costa,

Nanyang Technological University,

Singapore

Reviewed by:

Sarah Elizabeth Ogburn, United States Geological Survey (USGS), United States Christina Widiwijayanti, Earth Observatory of Singapore,

Singapore

*Correspondence: Eisuke Fujita fujita@bosai.go.jp

Specialty section: This article was submitted to Volcanology,

a section of the journal Frontiers in Earth Science

Received: 09 January 2020 Accepted: 18 May 2020 Published: 10 July 2020

Citation:

Fujita E, Ueda H and Nakada S (2020) A New Japan Volcanological Database. Front. Earth Sci. 8:205. doi: 10.3389/feart.2020.00205
Keywords: event tree for volcanic crises, INeVRH, JVDN, observation, numerical simulation, countermeasures, database

\section{INTRODUCTION}

In Japan, there are 111 active volcanoes (Figure 1), many of which potentially produce hazards and pose risks due to future eruption. Both for mitigation and research purposes, we operate volcano monitoring networks at 50 volcanoes that are managed by various agencies, universities, and institutions. As a consequence, data obtained through monitoring are dispersed across various institutions and in various data formats; therefore, we need to build a common platform to share these various datasets to improve mitigation techniques and to better understand volcanic processes. Doing so will allow us to enhance eruption forecast, hazard evaluation, and risk mitigation.

Our main goal is to build event tree frameworks during volcanic crises to estimate probabilities of possible outcomes of volcanic unrest, which is supported by observational datasets and numerical simulation results, as well as taking into account exposure and vulnerability data. We will construct event trees for volcanic crises using the method proposed by Newhall and Hoblitt (2002) as a standard tool for evaluating volcanic activity to assess hazards and risks as a part of crisis management planning. The event tree systematizes a way to estimate the probabilities of various volcanic phenomena, of which nodes and branches express the subsequent relationships from prior events to final outcomes. In this way, we try to provide more information more quantitatively about the probability of branching at the nodes, i.e., which way the situation will develop. We categorize the event tree into three sections: observation, forecast, and countermeasures (Figure 2). The observation section corresponds to the evaluation of volcanic activity, the forecast section corresponds to the branching of volcanic hazards, and the countermeasures section corresponds to the risk evaluation based on exposure and vulnerability. 


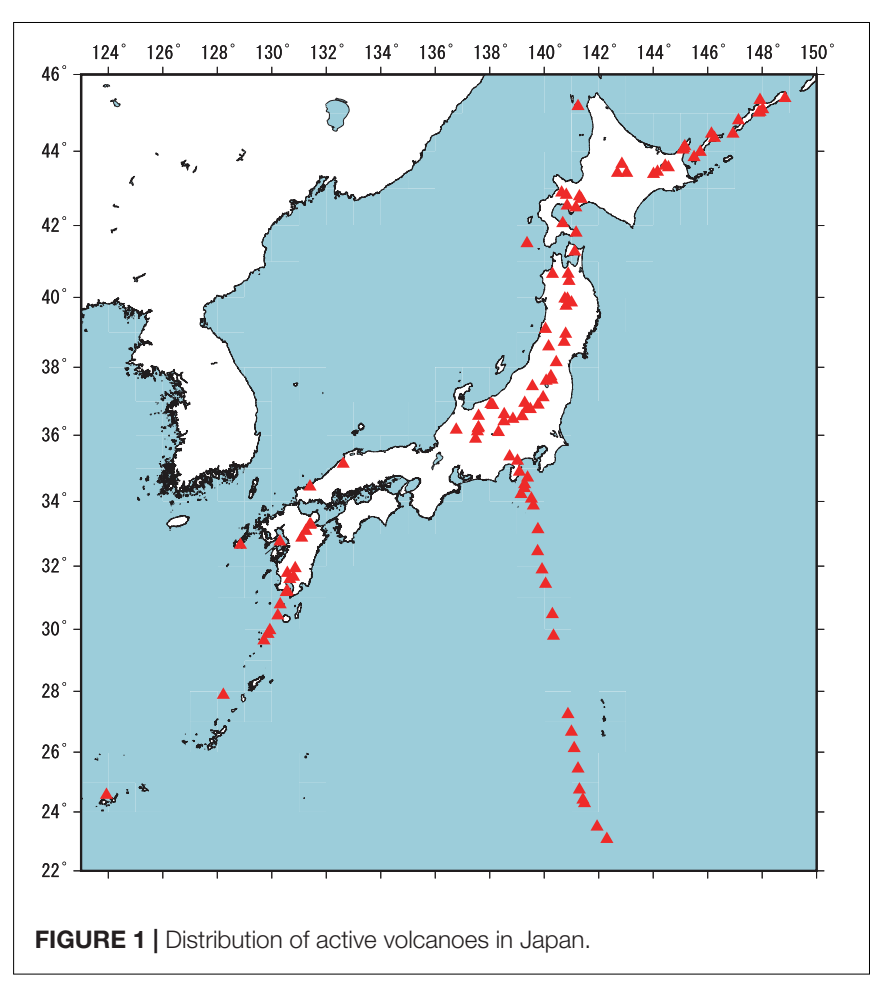

The Ministry of Education, Culture, Sports, Science and Technology (MEXT), Japan, has recently launched a new research project, entitled the "Integrated Program for Next Generation Volcano Research and Human Resource Development (INeVRH)" to run from 2016 to 2025. This project consists of four themes, A: Developing a Data-Sharing System of Volcano Observation Data, B: Development of Cutting-edge Volcano Observation Technology, C: Development of Forecasting Technologies for Volcanic Eruptions, and D: Development of Volcano Disaster Countermeasure Technology. The data-sharing system distributed by theme A is the Japan Volcanological Data Network (JVDN). JVDN plans to archive various kinds of data, that is, seismic, geodetic, geochemical, geological, and petrological data. The design for the JVDN system and the data flow is shown in Ueda et al. (2019). Details of the JVDN system are introduced in the next section. Theme $\mathrm{B}$ produces the observational data in various categories, namely, Muon, InSAR, optical remote sensing, volcanic gas, and geophysical campaign observation. These are also stored within JVDN. For the forecasting topic, theme $\mathrm{C}$ focuses on geological, petrological data, and also numerical simulation of volcanic phenomena, the details of which are explained in sections "Geological and Petrological Data" and "Numerical Simulation Data" of this paper. For the countermeasure information, real-time evaluation of volcanic activity and outreach information such as movies of lectures will be provided based on the research in theme D (Nakada et al., 2019).

Currently, we are in the initial development stage of the JVDN database linking all of the observations, forecasting, and countermeasures, encompassing themes of A-D. We have developed a basic platform to share and to realize static linkage of these for risk management (e.g., hazard maps) and dynamic linkage for crisis management (e.g., updating information about ongoing damage). In this paper, we will summarize the outline of our ongoing project of JVDN database development.

\section{OBSERVATION DATA}

We have various kinds of data from observation networks. The Japan Meteorological Agency (JMA) is responsible for issuing warnings and conducts volcanic observation at 50 volcanoes for the purposes of monitoring. Universities also operate observation networks at some active volcanoes for academic research. The National Research Institute for Earth Science and Disaster Resilience (NIED) manages a V-net at 16 volcanoes as a standard volcano observation network, equipped with a borehole highsensitivity velocity seismometer, borehole tiltmeter, broadband seismometer, and Global Navigation Satellite System (GNSS). The Geospatial Information Authority of Japan (GSI) is responsible for GEONET, the GNSS network encompassing all of Japan. These data are shared between the related organizations, and some data are open to the public or can be used for scientific purposes through registration with each individual system (Ueda et al., 2019).

For the evaluation of volcanic activity and scientific research, the analysis of multi-disciplinary data is pertinent for understanding the state of volcanoes. Our new data platform, JVDN, mainly provides these various kinds of volcanological data, some of which are raw data, while others are meta-data such as the indices about the location, data owner, and their instrument information (Figure 3).

For example, raw seismic data is distributed in WIN or WIN32 format, a standard format in Japan (Urabe, 1994). WIN/WIN32 data can be converted into international standard formats, like SAC, SUDS, ASCII, etc., using conversion tools, and users can treat the data as they wish. Ground deformation data from tiltmeters and strainmeters are also stored in WIN/WIN32 format, while GNSS data are stored in RINEX or in meta-data. Discussions are currently underway for other observation data such as magnetic, electric, and gravity observations to determine the most effective methods for analysis and storage.

All these data are designed to be compliant with WOVOdat (Newhall et al., 2017), which has been prepared mainly by the Earth Observatory of Singapore, Nanyang Technological University. WOVOdat distributes data and also analysis visualization, query, and analysis tools with GUI interfaces. Experiences in each volcano observatory and historical volcanic eruptions at a singular volcano are not sufficient to judge forthcoming activity. Therefore, the sharing and comparison of such information between observatories worldwide provide more evidence upon which to judge volcanic activity. The JMA sets the threshold for volcanic warning levels. If we share the unrest/precursory data of a volcanic eruption, we can compare it to other similar events at other volcanoes to estimate the probabilistic outcome of the ongoing observation data for the unrest in question. For 

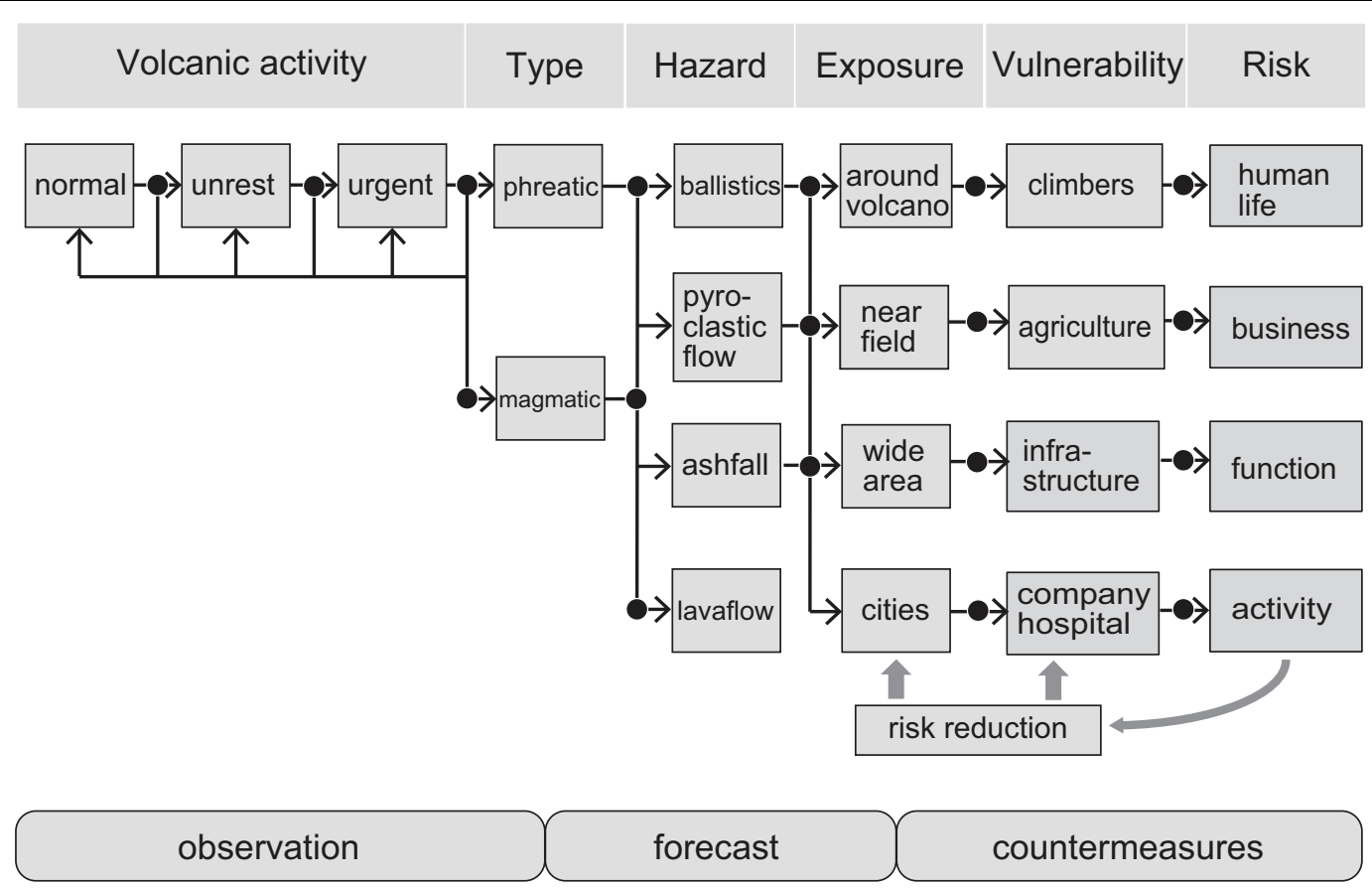

FIGURE 2 | Example of event tree for volcanic crises. We categorize this event tree into three parts: observation, forecast, and countermeasures. The quantitative threshold to judge the branching at each node is investigated by the new project, the Integrated Program for Next Generation Volcano Research and Human Resources Development. Our objective is to deal with all three categories and to propose an adequate countermeasure scheme.

example, at Aso Volcano, Japan, the threshold from level 2 (Do not approach the crater) to level 3 (Do not approach the volcano) is defined as: volcanic tremor amplitude of $4 \mathrm{micro} \mathrm{m} / \mathrm{s}$ in average tilt change, suggesting volcanic body expansion above $0.02 \mathrm{micro} \mathrm{rad} / \mathrm{h}$, and rapid increase in $\mathrm{SO}_{2}$ gas in excess of 2,000 tons/day (Japan Meteorological Agency, 2016). WOVOdat aims to support this data-sharing concept to improve eruption forecasting and for reaching a better understanding of volcanic processes, and our new JVDN database conforms to WOVOdat.

\section{GEOLOGICAL AND PETROLOGICAL DATA}

Geological and petrological studies provide important information about long-term volcanic activity. We obtained many drilling cores during the installation of V-net borehole sensors (Nagai et al., 2011, 2012, 2013a,b) and by geological surveys conducted at many volcanoes by universities and other institutions (Nakagawa et al., 2019). In addition, the INeVRT project is providing new drilling core data at other volcanoes. Precious core samples have to be preserved physically and archived digitally because they disintegrate easily.

National Research Institute for Earth Science and Disaster Resilience has established a drilling core center to manage and store drilling core samples and data in the JVDN database. Such cores can be utilized by researchers worldwide, and the database includes information on the locations, geologic and petrologic descriptions, column diagram, photographs, related background, analysis of results, and other information.

Geological data on units such as ashfall deposits provide information about eruption histories, including sequences of eruptions, modes and scales of eruption, and volumes and temporal development of each eruption (e.g., Suzuki et al., 2013). Drilling core and trench section analysis provide us with detailed information about individual historical eruptions, and we can estimate the branching probability based on multiple empirical data (Nakagawa et al., 2019).

In addition, petrological and laboratory experiment studies provide us with a great deal of information about both the subsurface and surface characteristics of magma behavior. For example, chemical compositions, water content, vesicularity, texture, etc., are the keys to understanding magmatic characteristics as well as the eruptive styles of each volcano. This information can be stored in the database for comparative study (Yoshimoto et al., 2004; Madarigal and Lucke, 2017).

FT-IR measurement of water content in a melt (Yasuda, 2014) is one example of datasets representing magma reservoir characteristics of chemistry, mineralogy, temperature, and water contents for 11 representative active volcanoes that have been archived so far. These petrological data provide information about the conditions and pressure under which magma was stored and can be converted to depth information. From the geophysical observation point of view, we can detect volcanic earthquakes and volcanic tremors beneath volcanoes, as well as their source depth. 


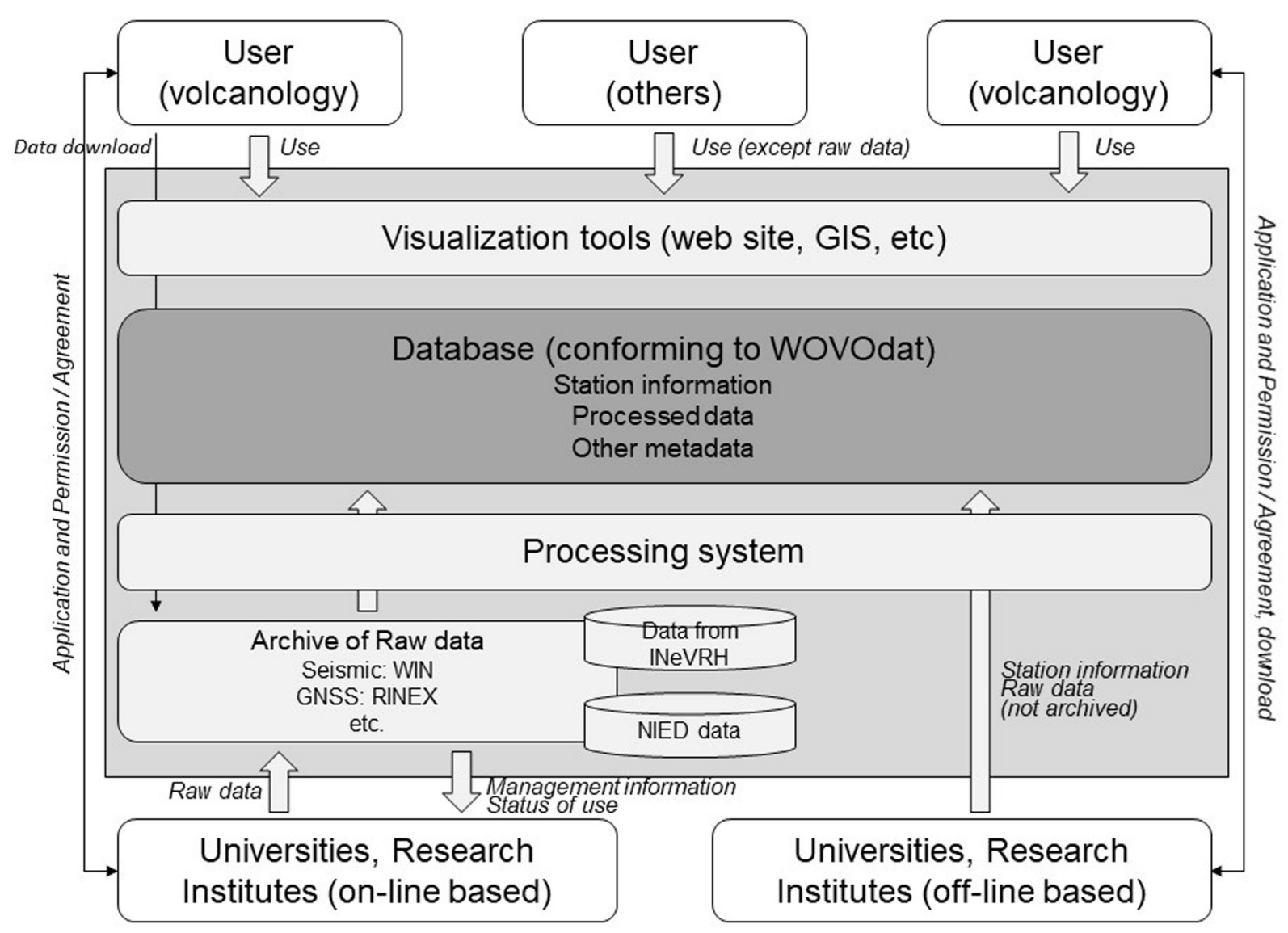

FIGURE 3 | Schematic concepts of the Japan Volcanological Data Network (JVDN).

Geophysical and petrological data give us information on source depth individually. Then, we can choose plausible source mechanisms, for example, vaporized fluid flow for shallow regions and super-critical fluid flow for deeper regions. It may be possible to employ more quantitative models.

Not only is the database designed for the analysis of historical eruptions, it is also designed to help evaluation of ongoing volcanic eruptions. One important objective is to identify the type of eruption, whether it is magmatic or non-magmatic, and to evaluate the possibility of a successive larger eruption event. A quick analysis of volcanic ash, that is, whether it includes juvenile magmatic particles or not, is the key to forecasting the ongoing eruption (e.g., Gaunt et al., 2016). To this end, equipment for automatic ash collection and analysis is under development (Miwa et al., 2018). This enables the precise sequence of the ashfall deposit to be analyzed with time stamping. In addition, ash particles are automatically analyzed and classified in terms of color and shape through an artificial intelligence (AI) system, and the equipment automatically reports the result of the component analysis, allowing the existence of magmatic particles to be assessed in real time. These results will also be uploaded to the JVDN database and will be used for the evaluation of ongoing volcanic activity as well as for countermeasure planning.

\section{NUMERICAL SIMULATION DATA}

Numerical simulation is used to evaluate complex volcanic phenomena consisting of both subsurface magmatic processes and surface hazards. In our project, we are building a volcanic hazard evaluation system that enables parallel evaluation of various volcanic hazards, including lava flow, ashfall, ballistics, and others, based on common input parameters such as flux rate (Fujita et al., 2019). Each numerical simulation code is being developed, respectively, and the types of input parameters are set for each individual simulation code. Some background data, e.g., digital elevation maps (DEM) and wind profiles, can also be stored and shared for use in various numerical simulations.

In many cases, numerical calculation is time-consuming, especially for the simulation of complex phenomena like a volcanic plume and multi-phase lava flow. These outputs should also be stored in the relational SQL database associated with the calculation conditions. To express probability in volcanic hazard and risk, we conduct multiple sessions of numerical simulation under plausible sets of input parameters and process these results statistically.

This database of calculation results will also link volcanic hazard to exposures and vulnerability (Fujita et al., 2019). The hazard information is expressed as the inundated area, time, 


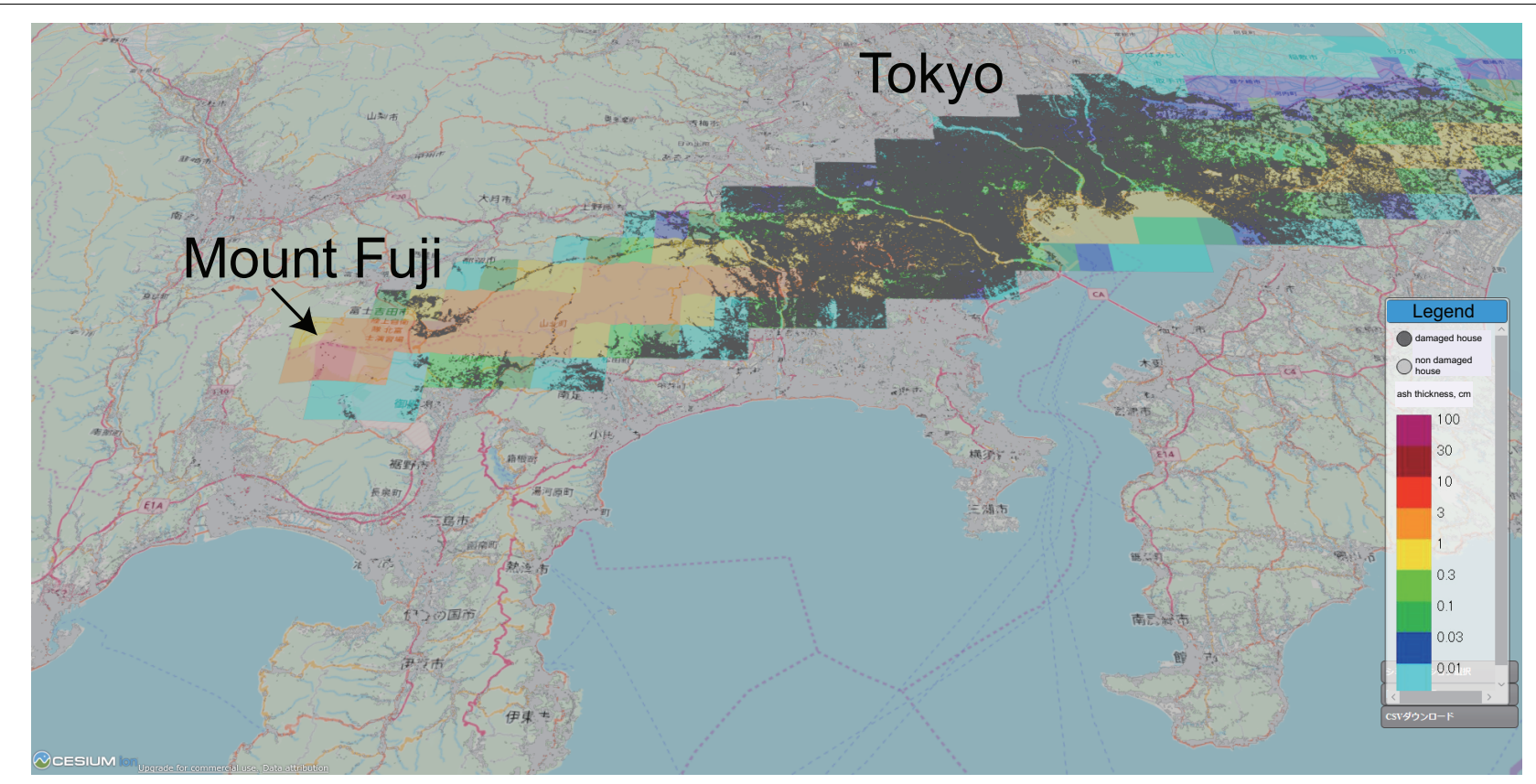

FIGURE 4 | An example of Mount Fuji ashfall simulation by JMA-RATM. The eruption plume was assumed to have the parameters of the Hōei eruption, and the wind profile in December 2016 was applied. The legend indicates the thickness of ashfall after $6 \mathrm{~h}$ from the onset of eruption. Gray makers show the buildings, while dark gray markers show those covered by ashfall.

velocity, and other characteristic properties for each type of hazard. As both databases are so-called big data, we need high-speed databases. We convert all of the information in these data into the OGC๑, 2020 Moving Features Simple CSV format ${ }^{1}$, which enables quick and easy handling. They can also be visualized by using a Geographical Information System (GIS) to plot and overlay them on exposures and vulnerabilities, e.g., the distribution of residential areas, roads, and infrastructure. Through this visualized information, we can estimate the risk of volcanic hazard quantitatively at the target location, and this information is also useful for countermeasures such as the formulation of evacuation plans by disaster mitigation authorities.

Here we introduce some case examples. One of the most widespread and pernicious volcanic hazards is ashfall. Ashfall dispersion is calculated by the JMA-RATM model (Shimbori, 2016). Here, we propose an example of an ashfall due to a Mt. Fuji eruption (Figure 3) in which we assume the initial condition of being the same size as the Plinian eruption of Hoiei in 1707. Ashfall distribution is strongly controlled by the height of plume and the local wind profile. In the JMA-RATM model, the numerical simulation refers to the weather-forecasting program and obtains detailed distributions. At present, the mesh size of the calculation is $5 \mathrm{~km} \times 5 \mathrm{~km}$, and this will be reduced to a $2 \mathrm{~km} \times 2 \mathrm{~km}$ area to provide more detailed information.

We obtain quantitative information of the ashfall deposit for each mesh from the numerical simulation. For risk management, this hazard information can be coupled with the exposure and

${ }^{1}$ http://www.ogc.org/ogc/Document vulnerability information (Figure 4). In general, the simulation mesh and archived mesh in the database are different from each other, so we need to match these different geometries to estimate the inundation area (Figure 4 in Fujita et al., 2019). The building distribution database provided by the Center for Spatial Information Science, The University of Tokyo (2010) is an example of static objects, and it has a much higher resolution than those of the numerical simulation. For the combination of hazard simulation and exposure databases, we need to synchronize the size and geometry of the meshes, applying intersection judgment and interpolation. Our future plan is to provide more quantitative information about the hazard and its risk, for example, using an agent-based model to integrate the ashfall simulation with dynamic information such as dynamic real-time data on humans and transportation. By doing so, we can propose efficient plans for logistics as part of crisis management.

In general, lava flows are less dangerous than the other volcanic hazards, since generally, the flow velocity is not very high, and the damage to human life itself is not very serious. However, a lava flow destroys the surrounding terrain permanently, so the damage inflicted on properties, public facilities, roads, and other infrastructure can be catastrophic. Some examples of lava flow simulation around Mount Fuji are also overlaid on the building infrastructure map (Figure 5) using LavaSIM (Hidaka et al., 2005). Most of the important transportation facilities in Japan go through this area, so there would be major economic ramifications if it is damaged by lava flow. A very threatening lava flow occurs when lava flows southward, destroying Shinkansen (bullet train) rail tracks and the Tōmei highway, which are the logistics arteries of Japan. 

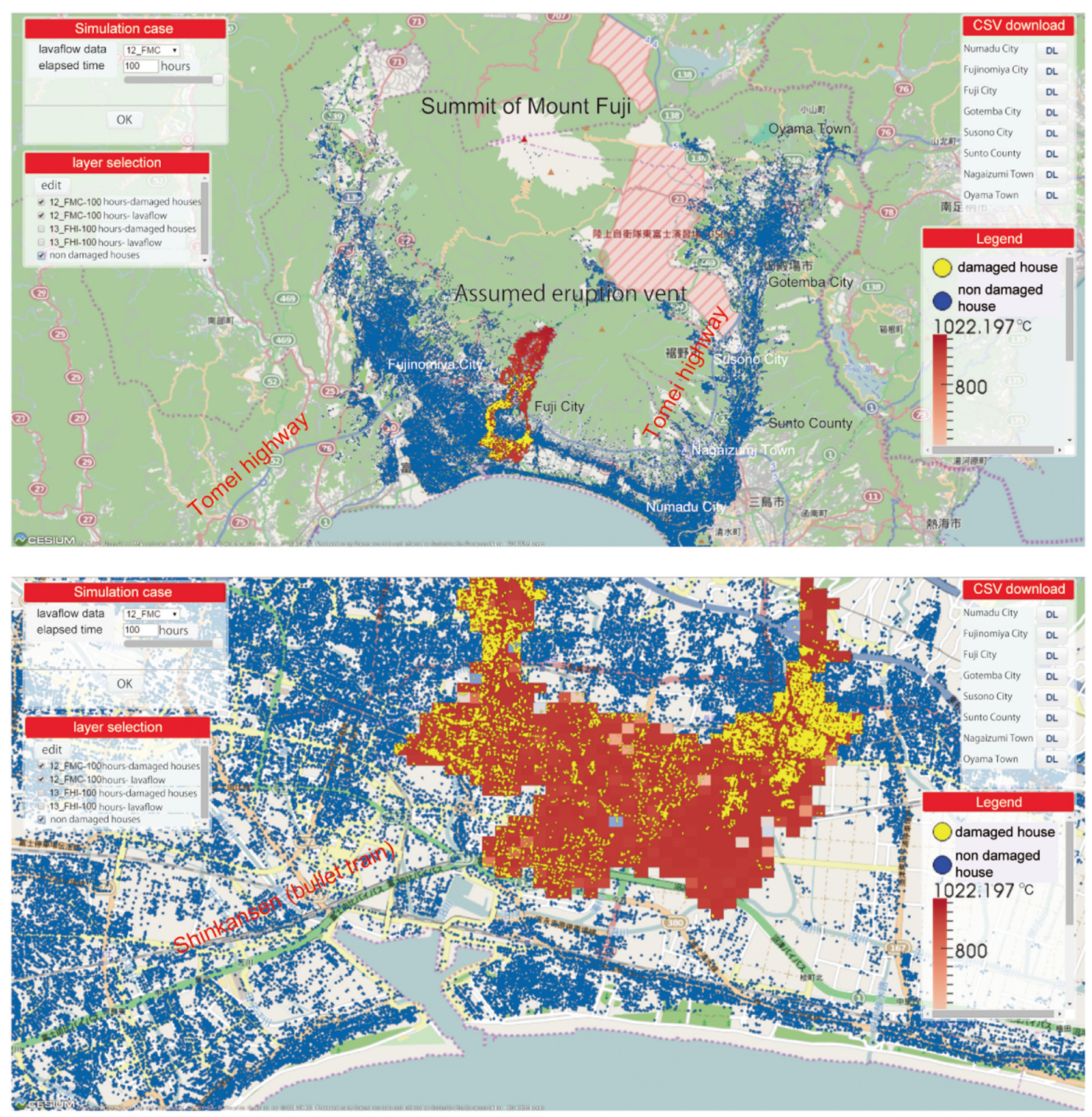

FIGURE 5 | An example of Mount Fuji lava flow simulation using LavaSIM (Hidaka et al., 2005). Blue markers indicate the location of buildings, and red markers show the lava-inundated cells. Yellow markers show the buildings damaged by lava flow. Eruption vent is assumed at the southern flank of Mount Fuji, and the lava flow runs toward the southern flank, damaging the important transportation facilities, Shinkansen (bullet train) and the Tōmei highway, the economic artery of logistics in Japan.

We can delineate the impacted area and estimate the available time before the lava flow impacts and formulate a plan for countermeasures.

We experienced a tragedy caused by ballistics in the eruption of Ontake, Japan, in 2014. Unfortunately, there were many tourists around the summit crater when the phreatic eruption suddenly occurred (Nagano Prefectural Police, 2014; Tsunematsu et al., 2016). Even though it is difficult to issue a warning for a sudden phreatic eruption, it will be essential to understand the risk of ballistic impacts and to make plans for evacuation and shelters around the summit area. We apply the ballistic simulation model using Ballista (Tsunematsu et al., 2014), which can produce outputs regarding the deposits' distribution, energy, and trajectories. 
Volcanoes are popular tourist hotspots, and it is important to mitigate possible hazards that can affect volcano climbers. Lessons learned from the tragic Ontake eruption initiated an investigation to obtain real-time tracking of climbers along trails on Mount Fuji trails performed at different times (Tanaka et al., 2018). Tracking devices (beacons) were distributed to each climber, whereby the receivers installed along the trails detected the real-time location of climbers. This dataset shows the speed of the climbers' traffic flow during the most crowded season. A combination of ballistic simulation and this dataset provides a countermeasure plan against ballistics hazards, e.g., the adequate distribution and size of huts and the route to an evacuation path.

We will also evaluate other volcanic hazards such as pyroclastic flow, lahars, etc., and plan to add these to the volcanic disaster evaluation system (Fujita et al., 2019).

\section{COUNTERMEASURE INFORMATION DATA}

Volcanologists have information about observation and forecasts for volcanic activities and hazards; however, these outputs are too specialized and difficult to be understood by the general public and therefore are not useful in practical volcanic hazard mitigation procedures for authorities and the general public (Nakada et al., 2019).

As an example, for the quick detection of ashfall distribution and component analysis, NIED developed an informationsharing system via SNS, named “Min'na de kazan," meaning that everyone reports about volcanic activity. Users can upload ashfall information about thickness, ash color, etc., and plot this on a GIS system. We can grasp the distribution of ashfall in real time and can use this to produce contour maps to identify ashfall hazard distribution. This information can be applied to evaluating the damage by ashfall, e.g., against electric power supply lines, roads, railways, and agriculture.

In addition, we are also developing digital volcanic hazard maps, which are converted from the original paper-based volcanic hazard maps issued by individual local governments and are digitized in a GIS-applicable format. Using a combination of hazard maps and social and infrastructure geospatial layers, we can support the countermeasure planning of local governments.

Under our plan, the countermeasure database will also include instructions on how to interpret the observation data and numerical simulation results, some lecture materials about volcanoes for the general public, digital contents including movies of volcanic phenomena, and some standard operating procedure (SOP) information for volcanic disaster management, available for local governments.

\section{CONCLUSION}

The ultimate goal of the INeVRH project is to perform evaluation of forthcoming volcanic activity and hazards through the automatic assimilation of observation data. The observation data and its primary data analysis will be stored in the JVDN system. Together with geological and petrological data, these data will be set automatically and/or manually as input to execute various volcanic hazard simulations. Simulation results will then be combined with exposure and vulnerability data to evaluate the risk, which will be utilized on the system as countermeasure information for risk reduction. Since, in most cases, observation data are not sufficient to regulate all input parameters required to run volcanic hazard simulation, some assumptions are used. To obtain the uncertainty and the applicability of the model, we first performed various simulations using the possible range of input parameters. The hazard and risk evaluation are performed using event tree analysis. The most difficult but important part is to obtain threshold values that define toward which branch of the event tree the activity will continue, especially during volcanic crises. We must also remain cognizant that the threshold may not work for a specific volcano, so we should also obtain it at other volcanoes to determine the general applicability. Developing the new Japan volcanological database system capable of integrating observation, forecast, and countermeasure strategy is a challenging task.

\section{DATA AVAILABILITY STATEMENT}

All datasets generated for this study are included in the article.

\section{AUTHOR CONTRIBUTIONS}

EF conducted general management of INeVRH projects with colleagues, was leading theme $\mathrm{C} 3$, the numerical simulation project to develop the volcanic hazard evaluation system, and wrote the manuscript. HU developed the JVDN system and created the figure illustrating the JVDN system. SN managed the countermeasure database project. All authors contributed to the article and approved the submitted version.

\section{FUNDING}

This research was funded by the Integrated Program for Next Generation Volcano Research and Human Resource Development, Ministry of Education, Culture, Sports, Science and Technology (MEXT), Japan (http://vivaweb2.bosai.go.jp/ kazan-pj/next-generation-volcano-pj-2019-jun).

\section{ACKNOWLEDGMENTS}

We are grateful to all participants in the INeVRH. Yosuke Miyagi developed countermeasure tools and provided us with information. 


\section{REFERENCES}

Center for Spatial Information Science, The University of Tokyo (2010). Joint Research Program at CSIS. Available online at: https://joras.csis.u-tokyo.ac.jp/ (accessed April 14, 2020).

Fujita, E., Iriyama, Y., Shimbori, T., Sato, E., Ishii, K., Suzuki, Y., et al. (2019). Evaluating volcanic hazard risk through numerical simulations. J. Disast. Res. 14:4. doi: 10.20965/jdr.2019.p0604

Gaunt, H., Bernard, B., Hidalgo, S., Proano, A., Wright, H., Mothes, P., et al (2016). Juvenile magma recognition and eruptive dynamics inferred from the analysis of ash time series: The 2015 reawakening of Cotopaxi volcano. J. Volcaonol. Geotherm. Res. 328, 134-146. doi: 10.1016/j.jvolgeores.2016. 10.013

Hidaka, M., Goto, A., Umino, S., and Fujita, E. (2005). VTFS project: Development of the lava flow simulation code LavaSIM with a model for three-dimensional convection, spreading, and solidification. Geochem. Geophys. Geosyst. 6:7. doi: 10.1029/2004GC000869

Japan Meteorological Agency (2016). Available online at: http://www.data. jma.go.jp/svd/vois/data/tokyo/keikailevelkijunn.html (accessed April 13, 2020).

Madarigal, P., and Lucke, O. (2017). Petrographic analysis of the volcanic bombs and blocks from Poas volcano: April-June 2017 eruption period. Rev. Geol. Am. Central 57, 149-159. doi: 10.15517/rgac.v0i57.30336

Miwa, T., Geshi, N., Ito, J., and Tanada, T. (2018). VOLCAT (Visual Observation Laboratory for Capturing Ash Transition) for automatic remote imaging of volcanic ash particle. Cities Volc. 10:173.

Nagai, M., Kozono, T., Nakada, S., Kobayashi, T., Kaneko, T., Fujita, E., et al. (2013a). Lithologic Features of the Borehole Cores from the Manzen and Hinamoridai Observation Wells, Kirishima Volcano, Southwestern Japan. Tech. Natl. Res. Inst. Earth Sci. Disaster Prevent. 374:49.

Nagai, M., Miyabuchi, Y., Miyoshi, M., Ikebe, S., Watanabe, K., Ohkura, T., et al. (2013b). Lithologic Features of the Borehole Cores from from the Ichinomiya and Hakusui Observation Wells, Aso Volcano, Southwestern Japan. Tech. Natl. Res. Inst. Earth Sci. Disaster Prevent. 373:48.

Nagai, M., Nakada, S., Takahashi, M., Asui, M., Ukawa, M., Kozono, T., et al. (2011). Stratigraphy and Lithologic features of the Borehole Core from the Onioshidashi Observation Well, Asama Volcano, Central Japan. Tech. Natl. Res. Inst. Earth Sci. Disaster Prevent. 357:32.

Nagai, M., Takahashi, M., Toda, Y., Mori, S., Nakada, S., Yasui, M., et al. (2012). Stratigraphy and Lithologic Features of the Borehole Core from the Takamine Observation Well, Asama Volcano, Central Japan. Tech. Natl. Res. Inst. Earth Sci. Disaster Prevent. 366:30.

Nagano Prefectural Police (2014). Police activity in the volcanic disaster at Mt. Ontake in 2014. Available online at: https://www.pref.nagano.lg.jp/police/ katsudou/ontake/index.html (accessed April 13, 2020).

Nakada, S., Miyagi, Y., Kubo, T., and Fujita, E. (2019). Conveying volcano information effectively to stakeholders - A new project for promotion of next generation volcano research. J. Disast. Res. 14:4. doi: 10.20965/jdr.2019.p0623

Nakagawa, M., Matsumoto, A., Kobayashi, K., and Wada, K. (2019). Comparative Petrological Studies of 1962 and 1988-1989 Eruptions of Tokachidake Volcano,
Japan: A Case Study for Understanding the Relationship Between Eruption Style and Magma Processes. J. Disast. Res. 14:5. doi: 10.20965/jdr.2019.p0766

Newhall, C. G., Costa, F., Ratdomopurubo, A., Venezky, D. Y., Widiwijayanti, C., Thin Zar Win, N., et al. (2017). WOVOdat - An online, growing library of worldwide volcanic unrest. J. Volcanol. Getherm. Res. 345, 184-199. doi: 10.1016/j.jvolgeores.2017.08.003

Newhall, C. G., and Hoblitt, R. (2002). Constructing event trees for volcanic crises. Bull. Volcanol. 64, 3-20. doi: 10.1007/s004450100173

OGC (2020). OGC( ) Available online at: http://www.ogc.org/ogc/Document (accessed April 13, 2020).

Shimbori, T. (2016). Tephra transport: modeling and forecasting. J. Volocanol. Soc. Jpn. 61, 399-427.

Suzuki, Y., Yasuda, A., Hokanishi, N., Kaneko, T., Nakada, S., Fujii, T., et al. (2013). Syneruptive deep magma transfer and shallow magma remobilization during the 2011 eruption of Shimoe-dake, JapanConstraints from melt inclusions and phare equilibria experiments-. J. Volcanol. Geotherm. Res. 257, 184-204. doi: 10.1016/j.volgeores.2013. 03.017

Tanaka, Y., Fukuzaki, A., Yasumaga, R., Hatanaka, M., Yoshimoto, M., and Honda, R. (2018). Efforts of hiker safety measures utilizing IoT in Mt. Fuji. Cities Volcanoes 14:604

Tsunematsu, K., Chopard, B., Falcone, J. J., and Bonadonna, C. (2014). A numerical model of ballistic transport with collisions in a volcanic setting. Comput. Geosci. 63, 62-69. doi: 10.1016/j.cageo.2013.10.016

Tsunematsu, K., Ishimine, Y., Kaneko, T., Yoshimoto, M., Fujii, T., and Yamaoka, K. (2016). Estimation of ballistic block landing energy during 2014 Mount Ontake eruption. Earth Planet. Sp. 68:88. doi: 10.1186/s40623-0160463-8

Ueda, H., Yamada, T., Miwa, T., Nagai, M., and Matsuzawa, T. (2019). Development of a Data sharing system for Japan volcanological data network. J. Disast. Res. 14:4.

Urabe, T. (1994). A common format for multi-channel earthquake waveform data. Seismol. Soc. Jpn. Meet. 2:384.

Yasuda, A. (2014). A new technique using FT-IR micro-reflectance spectroscopy for measurement of water concentrations in melt inclusions. EPS 66:34. doi: 10.1186/1880-5981-66-34

Yoshimoto, M., Fujii, T., Kaneko, T., Yasuda, A., and Nakada, S. (2004). Multiple magma reservoirs for the 1707 eruption of Fuji volcano. Jpn. Proc. Jpn. Acad. Ser. B 80, 103-106.

Conflict of Interest: The authors declare that the research was conducted in the absence of any commercial or financial relationships that could be construed as a potential conflict of interest.

Copyright (c) 2020 Fujita, Ueda and Nakada. This is an open-access article distributed under the terms of the Creative Commons Attribution License (CC BY). The use, distribution or reproduction in other forums is permitted, provided the original author(s) and the copyright owner(s) are credited and that the original publication in this journal is cited, in accordance with accepted academic practice. No use, distribution or reproduction is permitted which does not comply with these terms. 